beyond the four- to eight-week designs that are usual. This will probably only happen when the CSM and FDA insist on chronic studies to justify chronic prescription for chronic disorders.

ISAAC MARKS Metin Basoglu

Institute of Psychiatry

Maudsley Hospital

London SE5 8AF

References

KASVIKIS, I. M. \& MARKS, I. M. (1988) Clomipramine and exposure for OCD: 2-year follow-up. Journal of Anxiety Disorders, 4, 291-298.

Mawson, D., Marks, I. M. \& RAMm, E. (1982) Clomipramine and exposure for chronic obsessive-compulsive rituals: III. Two-year follow-up. British Journal of Psychiatry, 140, 11-18.

RAPOPORT, J., Elkins, R. \& MikKelsen, E. (1980) Chlorimipramine in adolescents with OCD. Psychopharmacology Bulletin. 16, 61-63.

\section{Near-death experience}

SIR: The article by Roberts \& Owen (Journal, November 1988, 153,607-617) called to mind a recent article by the philosopher Sir Alfred Ayer (1988), entitled "What I saw when I was dead". Sir Alfred's heart evidently stopped beating for four minutes after he choked on a slice of smoked salmon. On recovering he described the experience to a French friend: "Did you know that I was dead? The first time I tried to cross the river I was frustrated, but my second attempt succeeded. It was most extraordinary. My thoughts became persons." He says further, "I was confronted by a red light, exceedingly bright and also very painful even when I turned away from it. I was aware that this light was responsible for the government of the universe. Amongst its ministers were two creatures who had been put in charge of space."

In analysing the experience, Sir Alfred says it "could well have been delusive. A slight indication that it might have been veridical has been supplied by my French friend, or rather by her mother, who also underwent a heart arrest many years ago. When her daughter asked her what it had been like she replied that all she remembered was that she must stay close to the red light."

Sir Alfred's experience corresponds significantly to the description of NDE provided by Greyson (1985), incorporating parts of the 'transcendental component', i.e. encountering guides, coming to a border of no return (in this case the river), and parts of the affective component, i.e. being surrounded by a brilliant, warm (in this case, red) light. His recollec- tion, "my thoughts became people" is reminiscent of the experience that we, as psychiatrists, have with psychotic patients; i.e. there is a correspondence between their thoughts and the verbal productions/ forms of their hallucinated objects.

\section{Haverford State Hospital \\ Haverford \\ Pa. 19041 USA}

SUdHIR STOKES

\author{
References \\ AYER, A. J. (1988) What I saw when I was dead. National Revien', 40, \\ 38-40. \\ GrEYSON, B. (1985) A typology of near-death experiences. American \\ Journal of Psychiatry, 142, 967-969.
}

\section{Teenage depressive stupor}

SIR: We read with interest Powell et al's report of depressive stupor in a 13-year-old boy (Journal, November 1988, 153, 689-692). The authors' claim that there are no published descriptions of stupor in this age group is, however, incorrect, as case 4 of our series of ten cases of adolescent bipolar psychosis also presented with stupor at the age of 13 years (Hassanyeh \& Davison, 1980).

Royal Victoria Infirmary

FuAd Hassanyeh

KENNETH DAvisON

\section{Psychiatric Unit \\ General Hospital}

Newcastle upon Tyne NE4 6BE

\section{Reference}

Hassanyeh, F. \& Davison, K. (1980) Bipolar affective psychr. : with onset before age 16 years. Report of 10 cases. British Jour riv of Psychiatry, 137, 530-539.

\section{Defining personality disorder}

SIR: The validity of personality disorder (PD) as a mental illness has recently been the subject of several articles and letters (Blackburn, 1988; Chaloner, 1988; Cook, 1988; Gunn, 1988; Lewis \& Appleby, 1988), with the majority favouring its rejection. While statistical cluster techniques and reliable personalitytrait inventories support the existence of fixed deviant personalities, they cannot address the question of whether or not they are illness per se, as any such conclusion relies on the prior definition of mental illness. In the introduction to their study on the pejorative implications of the label 'personality 